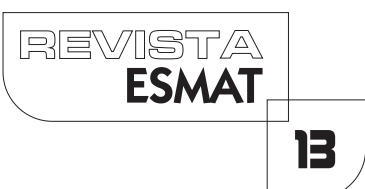

\title{
O ESTUDO DA DISCIPLINA DE DIREITOS HUMANOS NOS CURSOS DE DIREITO: DIAGNÓSTICO E PROPOSIÇÕES
}

\author{
THE STUDY OF HUMAN RIGHTS IN THE COURSES OF LAW: DIAGNOSIS AND \\ PROPOSITIONS
}

Ângela Issa Haonat

Doutora e Mestra em Direito. Professora no curso de Direito da Universidade Federal do Tocantins (UFT) e do Mestrado Profissional Interdisciplinar em Prestações Jurisdicional e Direitos Humanos (PPPJDH) - Universidade Federal do Tocantins (UFT) e Tribunal de Justiça do Estado do Tocantins (TJ/TO) por meio da Escola Superior da Magistratura Tocantinense (Esmat). Professora no curso de Direito da Faculdade Católica do Tocantins (FACTO). Advogada. E-mail: angelahaonat@uft.edu.br

Graciela Maria da Costa Barros

Mestra em Prestação Jurisdicional e Direitos Humanos. Servidora da UFT. E-mail: gracielabarros@uft.edu.br

Gustavo Paschoal Teixeira de Castro Oliveira

Doutor e Mestre em Direito. Professor no curso de Direito da Universidade Federal do Tocantins (UFT) e do Mestrado Profissional Interdisciplinar em Prestações Jurisdicional e Direitos Humanos (PPPJDH) - Universidade Federal do Tocantins (UFT) e Tribunal de Justiça do Estado do Tocantins (TJ/TO) por meio da Escola Superior da Magistratura Tocantinense (Esmat). Coordenador e Professor do curso de Direito do Centro Universitário Luterano de Palmas CEULP/NLBRA. Advogado. E-mail:gustavopaschoall @gmail.com

\section{Patrícia Medina}

Doutora em Educação. Mestre em Administração de Sistemas Educacionais. Pedagoga e bacharel em Direito. Professora no curso de Pedagogia da UFT e do Mestrado Profissional Interdisciplinar em Prestações Jurisdicional e Direitos Humanos (PPPJDH) - Universidade Federal do Tocantins (UFT) e Tribunal de Justiça do Estado do Tocantins (TJ/TO) por meio da Escola Superior da Magistratura Tocantinense (Esmat).E-mail: patriciamedina@uft.edu.br

\section{RESUMO}

Artigo resultado de pesquisa, com o propósito de compreender como a temática de direitos humanos é trabalhada e tratada pelos cursos de Direito, especificamente dos que se encontram na circunscrição do estado do Tocantins. 
Valeu-se de abordagem hipotético-dedutiva, com análise descritiva de conceitos e marcos teóricos sobre direitos humanos, cotejada com doutrina, legislação e normativas pertinentes, como Resoluções emitidas pelo Ministério da Educação, por meio do Conselho de Ensino Superior. Estruturou-se o artigo em três seções. Coube à primeira discorrer sobre a necessidade de se estudar e de tentar compreender os direitos humanos. A segunda seção tratou de tecer comentários sobre como os direitos humanos são e devem ser tratados nos cursos de Graduação em Direito. A terceira e última seção trouxe à baila questões locais e estaduais sobre o tratamento da temática de direitos humanos nos cursos de Graduação em Direito, no estado do Tocantins. Constatou-se a necessidade de maior cuidado com o assunto em questão, por ser considerado como fundamento para todas as ações desenvolvidas não somente pelas Instituições de Ensino Superior, mas também por todos os bacharéis em Direito, considerando-se aspectos éticos, sociais, jurídicos e políticos, bem como todos os possíveis desencadeamentos e consequências, seja em âmbito local ou global.

PALAVRAS-CHAVE: Direitos Humanos; Cursos de Direito; Estado do Tocantins; Instituições de Ensino Superior; Aspectos Éticos, Sociais, Jurídicos e Políticos.

\begin{abstract}
Research article with the objective of understanding how the human rights theme is worked and treated by Law Courses, specifically those that are in a constituency of the State of Tocantins. It was based on a hypothetical-deductive approach, carrying out a descriptive analysis of concepts and theoretical frameworks about human rights, checked against doctrine, legislation and pertinent regulations, such as Resolutions issued by the Education Ministry, through the Council of Higher Education. The article was structured in three sections. It was up to the first one to discuss the need of studying and trying to understand human rights. The second section dealt with comments on how human rights are and should be dealt in Undergraduate Law Courses. The third and last section brought local/state issues about the treatment of human rights theme in the Undergraduate Law Courses in the State of Tocantins. It was necessary to take greater care about the subject in question, since it is considered as a basis for all actions developed not only by Higher Education Institutions, but also by all law graduates, considering ethical, social, legal and political aspects as well as all possible triggers and consequences, whether at local or global level.
\end{abstract}

KEYWORDS: Human Rights. Law courses. State of Tocantins. Higher education institutions. Ethical, Social, Legal and Political Aspects. 


\section{INTRODUÇÃO}

Os cursos de Direito têm por finalidade precípua formar profissionais aptos ao exercício das diversas carreiras jurídicas existentes. Importante salientar que também são responsáveis por garantir desenvolvimento de competências e habilidades para tanto, por meio de raciocínio e pensamento crítico em abordagens trans e interdisciplinares.

Ponto crucial na formação geral e do espírito questionador é o contato com diretrizes de direitos humanos, pois elas auxiliam no aguçamento de inquietações éticas e sociais, no contexto dos sistemas de justiça.

Movido por tal questão, buscou-se o desenvolvimento do estudo de como a temática de direitos humanos é tratada pelos cursos de graduação em Direito, especificamente em todos os do estado do Tocantins. Essa delimitação é justificada, dentre outros motivos, devido ao fato de os coautores do artigo que ora se inicia comporem o Quadro Docente do Mestrado Profissional em Prestação Jurisdicional e Direitos Humanos, ofertado pela Universidade Federal do Tocantins (UFT), em parceria com o Tribunal de Justiça do Estado do Tocantins, por meio de sua Escola Superior da Magistratura Tocantinense (ESMAT), responsável pela capacitação e aperfeiçoamento de magistrados e servidores. Os coautores desenvolvem projeto de extensão intitulado "Formação de Professores para o Ensino de Direitos Humanos na Educação Superior do Estado do Tocantins", coordenado pela professora doutora Patrícia Medina. Este projeto encontra-se inserido no Projeto intitulado "Diálogos Interdisciplinares: Cidadania, Justiça Social e Direitos Fundamentais no Tocantins", financiado pelo TJTO junto com a UFT e intermediado pela Fundação de Apoio Científico e Tecnológico do Tocantins (FAPTO).

Todos os dados quantitativos foram extraídos de Relatório Técnico intitulado "Estudando direitos humanos: diagnóstico e proposições do processo ensinoaprendizagem em Direitos Humanos nos cursos de Direito, do estado do Tocantins", de autoria da mestra em Prestação Jurisdicional e Direitos Humanos, Graciela Maria da Costa Barros, ex-orientanda da professora doutora Patrícia Medina.

A temática do ensino de Direitos Humanos nos cursos de graduação em Direito, no estado do Tocantins, será analisada de acordo com o seguinte fio condutor: ( I ) ○ que são Direitos Humanos e qual a necessidade de estudá-los? Tal questionamento - bem como sua resposta justificada - é de suma importância para se buscar compreender a real necessidade em tornar os Direitos Humanos assunto que esteja inserido no cotidiano de todos os que procuram a formação superior em Direito; (2) ○ estudo de Direitos Humanos nos cursos de Direito: esta seção tem por escopo demonstrar como a temática de Direitos Humanos, tão necessária para formação humanista dos bacharéis em Direito, é ofertada; (3) A realidade do ensino-aprendizagem dos Direitos Humanos nos cursos superiores em Direito, no estado do Tocantins: com finalidade de ser trazer à lume diagnóstico e panorama geral; a seção em questão reflete sobre informações 
contidas nos Projetos Pedagógicos e Matrizes Curriculares dos Cursos de Direito ofertados no Estado do Tocantins, bem como sobre informações extraídas de questionários aplicados a acadêmicos, professores e coordenadores dos cursos de Direito; (4) Considerações finais e perspectivas encerram, momentaneamente, a pesquisa.

Utilizou-se, como recurso metodológico, o método hipotético-dedutivo, partindo da afirmativa de que os cursos de Direito, do estado do Tocantins, não atendem plenamente às normativas e aos anseios éticos, políticos e sociais, quando da oferta da temática de Direitos Humanos. Valeu-se, para tanto, de abordagem quantiqualitativa, devido à análise dos dados pesquisados e informações adquiridas por meio de aplicação de questionários em atores envolvidos. Utilizou-se de técnica indireta, com realização de pesquisa em doutrina pertinente; legislação e normativas expedidas pelo Ministério da Educação (MEC), por meio de seu Conselho de Educação Superior (CES); bem como análise de Relatório Técnico supramencionado.

Busca o presente estudo tentar responder à seguinte problematização: De que forma os cursos de Graduação em Direito, do estado do Tocantins, trabalham a temática de Direitos Humanos? Quais as opiniões dos atores envolvidos em tal processo?

\section{QUAL O MOTIVO DE SE ESTUDAR DIREITOS HUMANOS?}

A temática de Direitos Humanos sempre foi analisada e discutida pela humanidade. A necessidade de dominação e poder fez com que incontáveis situações de barbárie para com o próximo aflorassem no decorrer dos milênios. A História fornece tais registros: controle entre povos (egípcios e hebreus, romanos e judeus, europeus e nativos dos continentes americano e africano, dentre outros), perseguições da lgreja Católica na Idade Média, Inquisição, Nazismo, Fascismo, atrocidades cometidas por regimes militares em Estados da América Latina, Guerra do Vietnã, conflitos no Oriente Médio e intensificação de atos terroristas contra grandes potências mundiais a partir do início do Século XXI (GODOY, 2004; WOLKMER, 2005).

Extrai-se, de tais acontecimentos supramencionados, copiosa carga de emoções e sentimentos relacionados para com dores físicas e psicológicas, devido à clara constatação de sofrimento de milhões (para não se dizer bilhões) de pessoas, no decorrer dos tempos.

Todavia, há de se ressaltar que a própria humanidade, causadora de tais perversidades, também procurou proteger pessoas por meio de normativas locais e globais, fortalecendo, assim, direitos tidos como fundamentais e essenciais para o bemestar de todos. Citem-se documentos expedidos à época da independência das colônias norte-americanas, em 1776 (Declaração de Independência dos Estados Unidos da América); Revolução Francesa, em 1789 (Declaração dos Direitos do Homem e do Cidadão); e certo tempo depois, em 1948, a publicação da Declaração Universal dos Direitos Humanos (DUDH), pela Organização das Nações Unidas (ONU), 
Organização Internacional de caráter humanista, criada em 1945'. A quase totalidade de Estados atualmente existentes encontra-se vinculada à referida Organização, que tem por escopo garantir a manutenção da paz mundial e fomentar o desenvolvimento global, estribado em diretrizes vinculadas aos Direitos Humanos.

Para tanto, inúmeros tratados em âmbito internacional foram e são firmados a cada ano. Tais vínculos são imprescindíveis para se garantir a coexistência de nações e povos. Esses instrumentos devem levar em consideração o que solicita os Direitos Humanos. Trata-se de fácil e, ao mesmo tempo, difícil tarefa, pois, para sua efetivação, devida carga política deve ser conferida, para que alcance tudo e a todos, desde os grandes centros de Estados tidos como desenvolvidos aos mais longínquos rincões daqueles em desenvolvimento.

Hunt afirma que igualdade e universalidade devem ser enrobustecidas politicamente, com a devida participação dos que as detêm (2007). Bobbio, no mesmo sentido, ratifica sobre a importância da sistematização política para com o assunto, com o fito de garantir a forma mais justa de se assegurar a prática e de evitar a violação de tais direitos, devidamente previstos em Cartas Internacionais (2004, online). Mas, o que vêm a ser Direitos Humanos?

Trata-se de verdades autoevidentes, cristalizadas pelo período de I 50 anos de lutas por direitos essenciais a qualquer ser humano, por meio de apelos emocionais que reverberam no âmago de cada um deles ativados pela empatia, ou seja, pela identificação intelectual e/ou afetiva entre sujeitos, como, por exemplo, situações que versam sobre liberdade, igualdade, vida, autonomia do próprio corpo (HUNT, 2007). Hunt estabelece que "conhecemos o significado de Direitos Humanos porque nos afligimos quando são violados. As verdades dos Direitos Humanos talvez sejam paradoxais nesse sentido, mas apesar disso ainda são autoevidentes" (HUNT, 2007).

Os Direitos Humanos, para Silva, não podem ser confundidos com direitos naturais - concernentes à própria natureza humana -, pois decorrem das relações sociais, somando-se a isso os fatores tempo e cultura. Acrescenta que não se pode equivocar também com os direitos fundamentais, pois estes se encontram imbricados com a figura do indivíduo isoladamente considerado(2005). Os Direitos Humanos possuem propensão universalista e supranacional, pois buscam garantir direitos tidos como essenciais para todos os seres humanos que habitam o globo terrestre, mesmo que moldados pelo relativismo e pelo multiculturalismo. Trata-se de um "processo em

' O texto original da DUDH fora rascunhado e redigido com a participação de 50 (cinquenta) Estados, em tempo aproximado de 02 (dois) anos. O referido documento conferiu devido caráter político aos direitos por ele abarcados. BARROS, Graciela Maria da Costa. Estudando direitos humanos: diagnóstico e proposições do processo ensino aprendizagem em direitos humanos nos cursos de direito do estado do Tocantins. Relatório técnico. Mestrado em Prestação Jurisdicional e Direitos Humanos, 2016. 
construção que carece sempre de guardiões para garantir sua proteção" (BARROS, 2016, p. 158). Mister se faz o acesso, por parte de todos, a informações alusivas aos Direitos Humanos. É situação imprescindível para a evolução humana. $\bigcirc$ processo educativo é o fio condutor para tanto. Valora-se e protege-se o que se conhece (BARROS, 20 16). Dias enfatiza que a educação é o "único processo de tornar humano os seres humanos" (2007, p. 44I, online). Arendt, por sua vez, afirma que a educação é instrumento de auxílio na responsabilidade para com o mundo e para com as futuras gerações ( | 997).

Estudar sobre assuntos correlacionados aos Direitos Humanos é direito e obrigação de todos. Devem-se estudar Direitos Humanos não somente para se ter acesso às informações correlacionadas aos direitos individuais, mas (principalmente) para se compreender como as atitudes dos indivíduos interferem no social, bem como as decisões de agentes políticos e governantes podem acarretar - ou evitar - prejuízos de grande monta para com a saúde, segurança, educação, bem-estar dos cidadãos, seja em âmbito local e/ou global.

Os documentos internacionais de proteção à pessoa humana e as normativas internalizadas no devido sistema jurídico interno só poderão ser apreciados e seguidos por meio da educação. Esta, por sua vez, auxilia na possibilidade de desenvolvimento e refinamento daqueles. Trata-se, portanto, de um sistema que se retroalimenta.

Rawls assevera que a educação auxilia no desenvolvimento e treinamento de habilidades e aptidões (RAWLS, 204) que auxiliarão na drástica (e por que não dizer total) diminuição das desigualdades sociais. A educação em Direitos Humanos, portanto, "é patrimônio da humanidade e substrato material da cidadania" (BITTAR, 2008).

A educação propicia o conhecimento necessário para que atores sociais (em nível local, nacional ou supranacional) possam tratar dos inúmeros assuntos que se encontram conectados com os Direitos Humanos, bem como oportuniza possibilidades de criação e implantação de políticas públicas que irão propiciar a concretização de objetivos e metas por meio da execução de planos de ações.

\section{OESTUDO DOS DIREITOS HUMANOS NOS CURSOS DE DIREITO}

A questão educacional é interdisciplinar por natureza. Contudo, para a pesquisa em tela, necessário se faz isolar o acesso à informação sobre Direitos Humanos por meio do processo ensino-aprendizagem ocorrido na graduação em Direito, no Brasil, mais especificamente no estado do Tocantins, com o fito de se buscar compreender como os envolvidos no processo (não) externam tais conhecimentos adquiridos na vida práticoprofissional, em âmbito regional/local. Tem-se, por escopo, compreender como os Direitos Humanos foram tratados, estudados e percebidos pelos bacharéis.

curso de Direito propicia, a quem o procura, diversas oportunidades quanto às carreiras jurídicas, como: Advocacia, Docência, Magistratura, Procuradoria, Defensoria Pública, Delegacia de Polícia, Promotoria de Justiça, Conciliação, dentre outras. Todas as 
referidas profissões - bem como inúmeras não citadas - possuem relevante importância para com o social, pois versam sobre conhecimento, vida, bens e liberdades. Logo, a responsabilidade ética do profissional do Direito é algo imprescindível e, ao mesmo tempo, visceral.

Todos os atos praticados por tais profissionais perdurarão tanto no tempo quanto na vida de todos os que deles depender (JONAS, 2006). Bittar atesta que "o leque de conhecimento do bacharel torna-o um agente social maleável, uma vez que o conhecimento das leis e das práticas institucionais públicas (...) torna-o um profissional com preparo suficiente para a compreensão das relações sociais (...)” (2006, p. 130). Logo, indissociável está o profissional do Direito para com as diretrizes dos Direitos Humanos, na eterna busca de se garantir meios necessários para a devida aplicação da justiça no mundo dos homens.

A oferta do curso de Direito, por Instituições de Ensino Superior (IES) interessadas, é regulamentada pelo Ministério da Educação (MEC), por meio, dentre outros, da Resolução n 9, de 29 de setembro de 2004, expedida pela Câmara de Educação Superior do Conselho Nacional de Educação (CNE/CES), fundamentada no art. 9 , § $2^{\circ}$, "c" da Lei $n^{\circ} 4.024$, de 20 de dezembro de $1961^{2}$, de acordo com Pareceres CES/CNE n० 776, de $1997^{3}$, n $n^{\circ} 583$, de $2001^{4}$, e $n^{\circ} 100$, de $2002^{5}$, considerando o contido nos Pareceres CES/CNE n 55, de $2004^{6}$, e e ${ }^{\circ} 21$ I, de $2004^{7}$.

$\bigcirc$ artigo $2^{\circ}$, caput, da Resolução supramencionada, dispõe que a organização do curso de Graduação em Direito se expressa por meio de seu Projeto Pedagógico (PP):

(...) abrangendo o perfil do formando, as competências e habilidades, os conteúdos curriculares, o estágio curricular supervisionado, as atividades complementares, o sistema de avaliação, o trabalho de curso como componente curricular obrigatório do curso, o regime acadêmico de oferta, a duração do curso, sem prejuízo de outros aspectos que tornem consistente o referido projeto pedagógico.

Em complemento, no que tange ao assunto ora abordado pelo presente estudo (Direitos Humanos nos cursos de Graduação em Direito), o art. $3^{\circ}$ impõe que a

\footnotetext{
${ }^{2}$ Fixa as diretrizes e bases da educação nacional.

${ }^{3}$ Orienta as diretrizes curriculares dos cursos de graduação.

${ }^{4}$ Orienta as diretrizes curriculares dos cursos de graduação.

${ }^{5}$ Orienta as diretrizes curriculares dos cursos de graduação, no que tange a carga horária.

${ }^{6}$ Orienta as diretrizes curriculares dos cursos de graduação em Direito.

${ }^{7}$ Reconsideração do parecer CNE/CES 55/2004, referente às diretrizes curriculares nacionais para o curso de graduação em direito.
} 
Graduação em Direito deve assegurar "sólida formação geral, humanística e axiológica (...) indispensável ao exercício da Ciência do Direito, da prestação da justiça e do desenvolvimento da cidadania". Percebe-se, portanto, a necessidade de uma formação que extrapole limites técnico-processuais e também vá ao encontro de questões sociais, políticas e culturais, no intuito de estabelecer as devidas conexões com diretrizes dos Direitos Humanos. $\bigcirc$ artigo $5^{\circ}$, I, frisa a necessidade de o curso de graduação em Direito contemplar até mesmo conteúdos e atividades que atendam a outras áreas do saber: "Antropologia, Ciência Política, Economia, Ética, Filosofia, História, Psicologia e Sociologia". O inciso II ressalta a necessidade de se atentar às "mudanças sociais, econômicas, políticas e culturais do Brasil e suas relações internacionais." $\bigcirc$ artigo $8^{\circ}$ trata da necessidade da participação do alunado em atividades complementares, enfatizando a transversalidade e interdisciplinaridade, até "com as ações de extensão junto à comunidade".

Encontra-se, portanto, em tais delineamentos oficiais, a importância e obrigatoriedade em se trabalhar temáticas que se encontram encadeadas com o solicitado pelos Direitos Humanos. Fica clara, portanto, a necessidade de uma formação que leve em consideração a conexão com outras áreas do saber, de acordo com o disposto pelo artigo $5^{\circ}, \mathrm{l}$.

Pelo estudo da Antropologia, o acadêmico é estimulado a compreender a correlação entre sociedade, cultura e Direito. A Ciência Política oportuniza o contato com teorias correlacionadas a poder e dominação no que tange à Teoria Geral do Estado (formas, sistemas de governo e regimes políticos). Estudos em Economia proporcionam a possibilidade de melhor compreensão da evolução do pensamento econômico, e de como tal área do conhecimento afeta social e juridicamente a vida de todos os seres humanos, por meio do estudo da macro e da microeconomia. A Ética, como ciência da conduta, oferta ensinamentos de como cada ser humano deve se portar em todas as situações da vida - pessoais, familiares, sociais e/ou profissionais. Trata do modo de ser, do caráter aceito em determinada sociedade em determinado espaço e tempo. Por meio da Filosofia, o corpo docente recebe um convite à reflexão sobre todos os atos, valores e normas expedidas pela humanidade, no intuito de se buscarem caminhos e instrumentos para se trazer ao mundo real o que se entende por justo no mundo das ideias. A História contribui com o registro de fatos e situações que trouxeram alterações/evoluções social, ética e cultural pelo decorrer dos milênios. A Psicologia auxilia numa melhor compreensão acerca do comportamento humano em situações normatizadas pelo Direito, como Direito de Família e Ciências Criminais. A Sociologia traz à baila os fundamentos teóricos e conceituais das Ciências Sociais, na busca de se compreenderem os fenômenos sociais, políticos e culturais das sociedades.

Frise-se que todas as áreas acima elencadas são de suma importância para a formação humanista do bacharel em Direito. Encontram-se, via de regra, dispostas em parte inaugural da Matriz Curricular (MC) do curso de graduação em Direito, e vinculadas ao Eixo de Formação Fundamental. Logo, os Direitos Humanos também são 
trazidos aos estudantes de Direito por meio de disciplinas tidas como interdisciplinares, no intuito de auxiliar/oportunizar no processo de ensino-aprendizagem das Ciências Jurídicas, de acordo com o contexto social e histórico. Não há como compreender e emitir juízo de valoração de situações como relativismo; universalismo; multiculturalismo; costumes; relações internacionais; direitos fundamentais; dignidade da pessoa humana; direito humanitário; refugiados; sistemas de justiça, ou até situações mais específicas, como abuso e exploração sexual de crianças e adolescentes; direitos da pessoa idosa; proteção e defesa dos direitos de pessoas com deficiências; a situação da mulher no decorrer dos tempos e na contemporaneidade; lésbicas, gays, bissexuais, travestis, transexuais e transgêneros (LGBT); perseguições advindas de regimes militares; direito à moradia; questões socioambientais; direito à alimentação e à segurança alimentar; presídios; movimentos negros; dentre inúmeros outros, devidamente correlacionados com o apregoado pelos Direitos Humanos.

Saliente-se que os Direitos Humanos também devem se encontrar permeados nas demais disciplinas que compõem os outros Eixos de Formação: Técnico-Jurídico e Prático.

Eixo Técnico-Jurídico, em geral iniciado já por volta do segundo período com as disciplinas de Direito Constitucional e Direito Civil, também deve propiciar oportunidades de estudos de situações vinculadas aos Direitos Humanos, no intuito de se integrar e sistematizar conhecimentos com vista numa efetiva prestação jurisdicional por meio de futuras ações dos até então estudantes de Direito.

O Eixo Prático deve garantir o contato com situações-problema - simuladas e reais para que o acadêmico vislumbre a imbricação entre teoria e prática, por meio dos estágios curriculares, pelo Trabalho de Conclusão de Curso (TCC) e pelas atividades complementares. Ressalte-se a importância do contato acadêmico com jurisdicionados que não possuem condições de arcar com despesas processuais e advocatícias. Tal situação auxilia até na compreensão do cuidado e atenção para com o próximo, que necessita de auxílio para com a vida, dignidade, bens e/ou liberdade.

Esses apontamentos são de suma importância para se compreender a necessidade de se tratar de Direitos Humanos por toda a MC de uma graduação em Direito. Não há de se conceber a ideia de se formar bacharéis para embates e lides processuais. Necessita-se formar mais que operadores, ou seja, mais pensadores críticos do Direito. Logo, clara está a necessidade de uma formação que abarque inúmeras áreas do conhecimento, em prol de uma eficaz prestação jurisdicional que considere, efetivamente, o que é solicitado pelos Direitos Humanos.

\section{A REALIDADE DO ENSINO-APRENDIZAGEM DOS DIREITOS HUMANOS NOS CURSOS SUPERIORES EM DIREITO NO ESTADO DO TOCANTINS: DIAGNÓSTICO}

A presente seção tem por escopo ofertar, em seu texto, dados quantiqualitativos 
sobre o ensino de Direitos Humanos nas graduações em Direito, no estado do Tocantins, com o fito de se buscar trazer à baila informações de como o assunto é tratado no mais novo Estado da Federação. Tal diagnóstico é de suma importância para se tentar compreender qual o caminho que deverá ser trilhado, com vista a contribuir, local e regionalmente, para com uma questão internacional.

Todas as informações que serão apresentadas são oriundas de Relatório Técnico intitulado "Estudando direitos humanos: diagnóstico e proposições do processo ensinoaprendizagem em Direitos Humanos nos cursos de Direito, do estado do Tocantins", de autoria de Graciela Maria da Costa Barros, mestra em Prestação Jurisdicional e Direitos Humanos, do Programa de Mestrado Profissional ofertado pela Universidade Federal do Tocantins (UFT), em parceria com o Tribunal de Justiça do Estado do Tocantins (TJ/TO) por meio de sua Escola Superior da Magistratura Tocantinense (ESMAT). Tratase - referido Relatório Técnico - de produto final apresentado pela mestra em questão, orientada pela professora doutora Patrícia Medina - Docente do Programa - quando da conclusão dos estudos para a obtenção do título.

Procuraram-se, para a construção da pesquisa ora apresentada, não somente estudos em marcos teóricos sobre Direitos Humanos, mas também compreender como o tema é tratado pelos cursos de Graduação em Direito, no estado do Tocantins, delimitação territorial feita com vista a contribuir com a educação em Direitos Humanos no referido Estado. Para tanto, PPs e MCs dos quinze cursos foram analisados. Houve, também, a aplicação de questionários tipo Survey, com finalidade de se buscarem dados "sobre características, ações ou opiniões de um determinado grupo de pessoas, indicado como representante de uma população alvo (...)" (FREITAS, online). Passa-se, a partir de agora, a discorrer sobre tais etapas da pesquisa.

\section{I. Análise dos projetos pedagógicos e das matrizes curriculares}

Essa observação teve, como força motriz, a seguinte hipótese: o não cumprimento das orientações normativas relativas ao ensino de direitos humanos nos cursos de Direito, do estado do Tocantins. Analisaram-se PPs e MCs de quinze das dezesseis graduações: sete no município de Palmas, capital do estado do Tocantins; uma no município de Gurupi; uma no município de Dianópolis; uma no município de Paraíso do Tocantins; uma no município de Guaraí; uma no município de Colinas; duas no município de Araguaína; e uma no município de Augustinópolis. Os quinze cursos pertencem a treze IES (um curso vinculado a uma IES de natureza pública municipal; três cursos de Graduação encontram-se vinculados a uma IES de natureza pública estadual, um curso de Graduação a uma IES de natureza pública federal, e dez cursos de Graduação em Direito são ofertados por IES de natureza privada - três de natureza confessional, duas católicas e uma Luterana). Das quinze instituições pesquisadas, onze disponibilizaram os PPs. As quatro demais, apenas as MCs. Considerando que a pesquisa se utilizou de técnica direta (questionário), fez-se necessária a submissão em 
Comitê de Ética e Pesquisa, que foi devidamente aprovada ${ }^{8}$.

Aplicou-se, para tanto, a técnica de análise de conteúdo proposta por Bardin, consistindo numa "hermenêutica controlada, baseada na dedução: a inferência. Enquanto esforço de interpretação, análise de conteúdo oscila entre os dois polos do rigor da objetividade a da fecundidade da subjetividade" (BARDIN, 20 I I). Barros afirma que a análise de conteúdo proposta por Bardin se difere da simples análise documental devido ao fato de aquela buscar realizar análise categórica ou temática, bem como esclarecimentos, por meio da inferência (20 | 6).

Para tanto, três indicadores foram definidos, de acordo com o solicitado pelo Plano Mundial de Educação em Direitos Humanos (PMEDH), e pela Resolução CNE n 0 I, de 2012, que estabelece diretrizes nacionais para a educação em direitos humano: (I) presença de disciplina autônoma; (2) tratamento inter e transdisciplinar: inserção nas ementas de outras disciplinas, inserção nas referências de outras disciplinas, formas diversas e específicas de inserção (objetivos gerais, competência a ser desenvolvida pelo acadêmico); inserção em estágios e práticas jurídicas; (3) desenvolvimento de projetos de pesquisa e extensão.

Constatou-se, após a realização da pesquisa, que quatorze cursos ofertam a disciplina de Direitos Humanos; onze trabalham de forma trans e interdisciplinar (quatro não informaram); e, quanto a projetos de pesquisa e extensão, seis responderam positivamente), quatro não informaram e cinco disseram não trabalhar.

Figura I - Indicadores e formas de tratamento dispensadas à temática de direitos humanos no processo de ensino-aprendizagem dados pelos cursos de Direito, do estado do Tocantins, com base na análise de conteúdo de Bardin, 2016.

\begin{tabular}{|c|c|c|c|}
\hline \multirow[t]{3}{*}{ CURSOS } & \multicolumn{3}{|c|}{ INDICADORES DAS FORMAS DE TRATAMENTO } \\
\hline & Trans e & Disciplinar & Projetos \\
\hline & Interdisciplinar & & Pesq. Exten. \\
\hline CURSOI & SIM & SIM & SIM \\
\hline CURSO II & SIM & NÃO & $\operatorname{SIM}$ \\
\hline CURSO III & SIM & SIM & SIM \\
\hline CURSO IV & SIM & SIM & SIM \\
\hline CURSO V & SIM & SIM & NÁO \\
\hline CURSO VI & SIM & SIM & NĂO \\
\hline CURSO VII & SIM & SIM & NĀO \\
\hline CURSO VIII & SIM & SIM & NÁO \\
\hline CURSO IX & SIM & SIM & SIM \\
\hline CURSO $\mathrm{X}$ & SIM & SIM & SIM \\
\hline CURSO XI & SIM & NÁO & NÁO \\
\hline CURSO XII* & $\mathrm{NI}$ & SIM & $\mathrm{NI}$ \\
\hline CURSO XIII* & $\mathrm{NI}$ & SIM & $\mathrm{NI}$ \\
\hline CURSO XIV* & $\mathrm{NI}$ & SIM & NI \\
\hline CUROS XV* & $\mathrm{NI}$ & SIM & NI \\
\hline
\end{tabular}

Fonte: Barros, 2016.

Legenda: $\mathrm{NI}$ - não informado.

${ }^{8}$ Por meio de Parecer Consubstanciado de $n^{\circ}$ 1.632.508, proveniente do Comitê de Ética em Pesquisa do Centro Universitário Luterano de Palmas - CEULP/ULBRA. 
Os dados quantitativos também podem ser mais bem visualizados por meio da figura abaixo:

Figura 2 - Formas de tratamento previstas nos PPs e MCs dos cursos de Direito, do Tocantins, e a quantidade de cursos identificada.

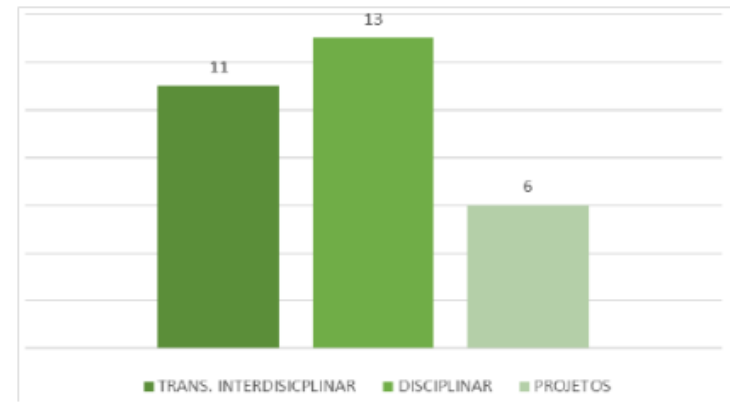

Fonte: Barros, 2016.

Constata-se, portanto, a presença da temática de Direitos Humanos em todos os cursos de Direito, do estado do Tocantins, com maior ou menor grau de intensidade quanto aos indicadores previamente definidos. Tais dados evidenciam que, de alguma forma, todos os cursos atendem às exigências legais. Constatou-se, também, heterogeneidade nos cenários pesquisados, no que tange à forma de inserção da temática de direitos humanos (disciplinar, trans e interdisciplinar, projetos de pesquisa e extensão).

\subsection{Análise das respostas dos questionários}

O questionário foi aplicado em I I IES, 3 não concordaram em participar, e uma não se manifestou. A pesquisa direta foi realizada entre os meses de agosto e outubro de 20 16, com a participação de 6I I indivíduos, assim distribuídos: 10 coordenadores de curso; 65 professores; e 536 alunos matriculados nos dois últimos períodos do curso $\left(9^{\circ}\right.$ e $10^{\circ}$ períodos). Geraram-se, com este quantitativo de entrevistas, mais de 34 mil dados.

questionário dos coordenadores foi assim disposto: 9 questões sobre direitos humanos e atuação profissional; 5 sobre sugestões e impressões acerca do tema; 2 sobre o curso; e 9 sobre dados pessoais e formação.

Dado interessante é sobre o contato de cada coordenador com a temática de direitos humanos, na graduação: $50 \%$ afirmaram que se deu de forma interdisciplinar; $30 \%$ por meio de projetos; e 20\% em disciplina. Outra questão levantada foi sobre o grau de satisfação de cada coordenador quanto à abordagem do tema no curso que 
administra. 70\% externaram insatisfação quanto ao processo ensino-aprendizagem para com os Direitos Humanos, afirmando que a temática necessita de maior e melhor aprimoramento no curso, seja pela oferta de disciplina obrigatória, seja de forma interdisciplinar ou por meio de projetos de pesquisa e de extensão.

Foi elaborada uma "nuvem de palavras", por meio do programa Tagui. Constatou-se a frequência das seguintes palavras: "Direito", "Temática", "Visão", "Insuficiente", "Humanos", "Discutida", "Acredito" e "Outras" (BARROS, 201 6, p. I07).

Constavam do questionário aplicado aos professores 7 questões sobre Direitos Humanos e atuação profissional; 4 sobre impressões e sugestões sobre o assunto; e 9 sobre informações pessoais e profissionais. Os professores assinalaram positivamente quanto à necessidade de se tratar da temática de forma trans e interdisciplinar, por meio de projetos de pesquisa e extensão. Todavia, assinalaram da necessidade de progressão quanto ao tema, até mesmo por meio de disciplina obrigatória (grande parte dos cursos oferta a disciplina de Direitos Humanos como optativa. Alguns com carga horária de 30 horas).

questionário aplicado aos alunos compreendia 8 questões sobre Direitos Humanos e 6 com informações pessoais. Inferiu-se o que se segue: parte relevante percebe o estudo dos Direitos Humanos somente no formato de disciplina específica (autônoma). Contudo, solicitam melhorias no que tange ao processo de ensinoaprendizagem, nas modalidades ensino (disciplinar e interdisciplinar), pesquisa e extensão.

\section{CONSIDERAÇÕES E PROPOSIÇÕES}

Assuntos abordados pelos Direitos Humanos (questões históricas, teóricoconceituais, técnico-processuais, e debates contemporâneos) são de vital importância na formação do profissional do Direito como ator social das Ciências Sociais e Aplicadas, considerando-se todo o trabalho a ser desenvolvido para com a comunidade.

Buscou a pesquisa em tela trazer à baila informações sobre a necessidade de se conhecer e estudar Direitos Humanos nos cursos de Direito. Para tanto, discorreu-se sobre questões teóricas e analisou-se produto final apresentado por Graciela Maria da Costa Barros, mestra em Prestação Jurisdicional e Direitos Humanos, do Programa de Mestrado Profissional ofertado pela Universidade Federal do Tocantins (UFT), em parceria com o Tribunal de Justiça do Estado do Tocantins (TJ/TO), por meio de sua Escola Superior da Magistratura Tocantinense (ESMAT).

Percebeu-se, por meio do estudo realizado, a necessidade de se aprimorar a forma de tratar a temática de Direitos Humanos nos cursos de Direito, do estado do Tocantins. Verificou-se, por meio de pesquisa documental e de aplicação de questionário, certa insatisfação por parte de coordenadores e professores; e, por parte dos alunos, certo desconhecimento da forma de abordagem do assunto.

A disciplina "Direitos Humanos" não é ofertada como obrigatória por todos os 
cursos. Alguns que disponibilizam ainda o fazem com uma carga horária reduzida (30 horas). Quando ofertada na modalidade optativa, pode não figurar com frequência, quando da disponibilidade semestral.

A temática Direitos Humanos, por mais essencial que seja, não se encontra bem definida, quando tratada de forma trans e interdisciplinar. Essa situação é abordada tanto por alunos quanto por professores. Por mais longínquo que certo assunto jurídico, dos Direitos Humanos, pareça estar (o que se vislumbra, num primeiro momento, em disciplinas de direito privado, por exemplo), sempre estará presente, considerando-se sua ligação com os direitos fundamentais, e estes com todos os ramos do Direito.

Faz-se necessário que os Direitos Humanos sejam mais notados nos cursos de Graduação em Direito. Eles já se encontram permeados em disciplinas propedêuticas (como, por exemplo, História do Direito, Antropologia e Sociologia Jurídica, Filosofia do Direito, Ética Profissional, Psicologia Jurídica), e específicas (Direito Civil, Direito Penal, Direito Constitucional, Direito Processual, Direito do Trabalho, dentre outras), e prático-profissionais (estágios, por meio do contato com os assistidos); bem como por meio de projetos de pesquisa e de extensão.

Algo evidenciado foi certo desconhecimento, por parte dos alunos, do quanto a temática de Direitos Humanos está permeada em todas as disciplinas do curso, seja de forma direta ou indireta. Tal fato pode ser justificado, considerando-se o que segue: imaturidade ao adentrar o curso de Direito; interesse exacerbado em situações que promovam lides e embates processuais; foco em lograr êxito no Exame da Ordem dos Advogados do Brasil e/ou em concursos públicos, o que aguça a mecanização do estudo.

Verifica-se, portanto, vasto e fértil terreno para ainda se fazer brotar a conscientização e sensibilização dos Direitos Humanos no mundo do Direito. Todos os atores envolvidos (IES, coordenadores, professores, acadêmicos) devem procurar meios para o efetivo estudo, conhecimento e aplicação dos Direitos Humanos. Os Direitos Humanos, uma vez percebidos, entendidos e aceitos, auxiliam o desenvolvimento social; fomentam a justiça, a liberdade e a solidariedade; contribuem para a igualdade e erradicação da pobreza; promovem o bem de todas as pessoas, fazendo cair por terra preconceitos e discriminações.

Ações conjuntas são imprescindíveis para tanto. Logo, hão de se promover e propiciar situações de encontros e debates, não somente entre todos os sujeitos envolvidos no processo, por meio de parcerias entre as IES, troca de informações, realizações de eventos com efetiva participação da sociedade; elevar a proposição de projetos de pesquisa e extensão; evidenciar a presença dos Direitos Humanos no cotidiano dos acadêmicos; estabelecer termos de cooperação com órgãos e entidades públicas, como Ordem dos Advogados do Brasil, Ministério Público, Defensoria Pública, Poder Judiciário, dentre outros.

Profissionais do Direito são importantes atores sociais para a disseminação de tais objetivos e metas, devidamente fundamentados no que solicitam os Direitos Humanos. 
Logo, devem-se promover oportunidades de se conhecer e valorar, para, posteriormente, saber fazer. Já dizia Reale (2002):

Diríamos que o Direito é como o rei Midas. Se na lenda grega esse monarca convertia em ouro tudo aquilo em que tocava, aniquilando-se na sua própria riqueza, o Direito, não por castigo, mas por destinação ética, converte em jurídico tudo aquilo em que toca, para dar-lhe condições de realizabilidade garantida, em harmonia com os demais valores sociais.

\section{REFERÊNCIAS}

ARENDT, Hannah. Entre o passado e o futuro. São Paulo: Perspectiva, 1997.

BARDIN, Laurence. Análise de Conteúdo. São Paulo: Edições 70, 201 I.

BARROS, Graciela Maria da Costa. Estudando direitos humanos: diagnóstico e proposições do processo ensino aprendizagem em direitos humanos nos cursos de direito do estado do Tocantins. 227 f. Relatório técnico. Mestrado em Prestação Jurisdicional e Direitos Humanos, 2016.

BITTAR, Eduardo C. B. (Coord.). Educação e metodologia para os direitos humanos. São Paulo: Quartier Latin, 2008.

. Estudos sobre ensino jurídico: pesquisa, metodologia, diálogo e cidadania. 2. ed. São Paulo: Atlas, 2006.

BOBBIO, Norberto. A era dos direitos. Trad. Carlos Nelson Coutinho. Rio de Janeiro: Campus, 2004. Disponível em: < http://www.mprj.mp.br/ documents/l 0227//4586286/a_era_dos_direitos.pdf > . Acesso em 5 jan. 2017.

BRASIL. Lei n 4.024, de 20 de dezembro de 1961. Disponível em: <http://www.planalto.gov.br/ccivil_03/leis/L4024.htm>. Acesso em 6 jan. 2017.

BRASIL. MINISTÉRIO DA EDUCAÇÃO. CONSELHO NACIONAL DE EDUCAÇÃO. Parecer CNE n 776/97. Disponível em: $<$ http://portal.mec.gov.br/setec/arquivos/pdf_legislacao/superior/legisla_superior_par ecer77697.pdf > . Acesso em 6 jan. 2017.

- Carga horária dos cursos de graduação. Disponível em: 
<http://www.cmconsultoria.com.br/legislacao/pareceres/2002/par_2002_0100_CE S.pdf>. Acesso em 6 jan. 2017.

- Diretrizes curriculares nacionais para o curso de graduação em direito. D i s p o níve I e $\mathrm{m}$ : http://portal.mec.gov.br/cne/arquivos/pdf/2004/ces0055_2004.pdf>. Acesso em 6 jan. 2017.

. Orientação para as diretrizes curriculares dos cursos de graduação. Disponível em: <http://portal.mec.gov.br/cne/arquivos/pdf/CES0583.pdf>. Acesso em 6 jan. 2017.

Reconsideração do parecer CNE/CES 55/2004, referente às diretrizes curriculares nacionais para o curso de graduação em direito. Disponível em: <http://www.abmes.org.br/arquivos/legislacoes/Par_CES_2l I_080704.pdf>. Acesso em 6 jan. 2017.

- Resolução $n^{\circ} 01$, de 30 de maio de 2012. Disponível em: <http://portal.mec.gov.br/index.php?option =com docman\&view=download\&alias

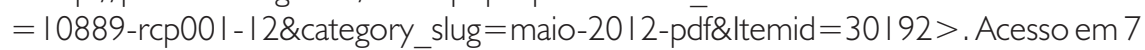
jan. 2017.

DIAS, Adelaide Alves. Da educação como direito humano aos direitos humanos como princípio educativo. In: SILVEIRA, Rosa G. et al (Coord.). Educação em direitos humanos: fundamentos teóricos-metodológicos. João Pessoa: Universitária, 2007. p. 44l. Disponível em: <http://www.dhnet.org.br/ dados/livros/edh/br/fundamentos /26_cap_3_artigo_04.pdf $>$. Acesso em 30 set. 2015.

FREITAS, Henrique M. R. de. (Coord.). Método de pesquisa survey. Disponível em: $<$ http://www.unisc.br/portal/upload/com_arquivo/metodo_de_pesquisa_survey.pdf $>$. Acesso em 9 mar. 2016.

GODOY, Arnaldo Sampaio de Moraes. Direito e história: uma relação equivocada. Londrina: Edições humanidades, 2004.

HUNT, Lynn. A invenção dos direitos humanos: uma história. Tradução de Rosana Eichenberg. São Paulo: Cia das Letras, 2007.

JONAS, Hans. O princípio responsabilidade: ensaio de uma ética para a civilização tecnológica. Rio de Janeiro: Contraponto, 2006.

RAWLS, John. O direito dos povos; seguida de "Ideia de razão pública revista". Trad. 
O ESTUDO DA DISCIPLINA DE DIREITOS HUMANOS NOS CURSOS DE DIREITO: DIAGNÓSTICO E PROPOSIÇÕES

Luís Carlos Borges. São Paulo: Martins Fontes, 2004.

REALE, Miguel. Noções preliminares de direito. 27. ed. São Paulo: Saraiva, 2002.

SILVA, José Afonso da. Curso de direito constitucional positivo. 25. ed. rev e ampl. São Paulo: Editora Revista dos Tribunais, 2005.

WOLKMER, Antônio Carlos. Fundamentos de história do direito. 3. ed. Belo Horizonte: Del Rey, 2005.

Recebido em: 07/06/2017

Aprovado em: 21/06/2017 
